$\overline{\text { Original }}$

\title{
Rapid and Simple Colorimetric Detection of Escherichia coli 0157:H7 in Apple Juice Using a Novel Recombinant Bacteriophage-Based Method
}

\author{
HOANG A. HOANG* , AND LE T. DIEN \\ Department of Biotechnology, Faculty of Chemical Engineering, Ho Chi Minh City University of Technology, \\ 268 Ly Thuong Kiet, District 10, Ho Chi Minh city, Vietnam
}

Received 4 September, 2014/Accepted 26 November, 2014

\begin{abstract}
In this study, a bacteriophage-based method for the colorimetric detection of E. coli 0157:H7 in apple juice was investigated. Firstly, a gene encoding Cytochrome c Peroxidase (CCP) chromogenic enzyme was inserted into a wild type PP01 phage genome to construct the recombinant PP01ccp phage that was used in the production of the chromogenic enzyme through specific infection into $E$. coli $0157: \mathrm{H} 7$. The method was then examined in the colorimetric detection of $E$. coli 0157:H7 in broth, and the appearance of $E$. coli 0157:H7 in broth was confirmed by the color change after a few minutes of the enzyme assay. Secondly, the method was investigated in the colorimetric detection of $E$. coli 0157:H7 in apple juice. A low $E$. coli 0157:H7 concentration as $1 \mathrm{CFU} \mathrm{mL}{ }^{-1}$ was detected in $15 \mathrm{~h}$ that was in a shorter time than in previous bioluminescence phage-based methods. Moreover, the method is much simpler compared to other previous phage-based methods since it enables detection without the need for expensive apparatus.
\end{abstract}

Key words : E. coli O157:H7 / Bacteriophage / Colorimetric detection / Apple juice.

\section{INTRODUCTION}

Enterohemorrhagic Escherichia coli (EHEC) can cause severe foodborne diseases due to the two toxins of Shiga toxin 1 and 2 (Stx1 and Stx2) produced by EHEC. Among serotypes of EHEC, E. coli O157:H7 is considered as the most important pathogen in relation to public health. It causes severe bloody diarrhea and hemolytic-uremic syndrome (HUS) in people. In the United States, about 73,000 cases of food-borne illness caused by E. coli O157:H7 have been reported per year (Mead et al., 1999). Animal feces are considered as the original source of E. coli $\mathrm{O} 157: \mathrm{H} 7$, and via many different routes, E. coli O157:H7 can infect human beings (Chekabad et al., 2013). Therefore, from the first outbreak of foodborne illness caused by $E$. coli O157:H7 in 1983, it has become important to detect $E$. coli $\mathrm{O} 157: \mathrm{H7}$ to prevent such outbreaks. By applying

*Corresponding author. Tel: +84-8-38639341, E-mail : hoang.a.hoang (a)hcmut.edu.vn the Sorbitol-MacConkey agar plate method (Fujisawa et al., 2000; Possé et al., 2008), low E. coli O157:H7 concentrations can be detected. However, the agar plate method is time consuming since it takes more than a day for the pre-cultivation and the formation of colonies on the agar plate. One of the approaches considered for shortening the detection time for $E$. coli O157:H7 is the use of polymerase chain reaction (PCR) for amplification of the stx 1 and stx2 genes (Jinneman et al., 2003; Fode-Vaughan et al., 2003). Although the method is rapid, it is inadequate for distinguishing the living cells from dead cells.

Apple juice is one of the most common fruit juices. While apple juice usually refers to the filtered and pasteurized product of apple pressing, unpasteurized apple juice (or apple cider) is still packed and consumed especially in the apple-producing regions in the world because with its $\mathrm{pH}$ of less than 4.6 there is considered to be low risk for the transmission of pathogenic bacteria. However, the infection of E. coli O157:H7 from consuming the unpasteurized fresh 
apple juice has been reported (Steele et al., 1982; Besser et al., 1993 and Cody et al., 1999).

The application of bacteriophages for detection of specific bacteria is advantageous owing to the high specificity of bacteriophages in host recognition. Until now, fluorescence- or bioluminescence-based detection methods utilizing bacteriophages for detection of $E$. coli O157:H7 have been investigated (Oda et al., 2004; Brigati et al., 2007). In those studies, the resulting fluorescence or bioluminescence could be detected using an epifluorescence microscope or a luminescence counter, respectively. Although both fluorescence- and bioluminescence-based detection methods allow selective detection of $E$. coli $\mathrm{O} 157: \mathrm{H} 7$ in less than one day, special apparatus are required to evaluate the results. Generally, it is easy and convenient to examine results by the colorimetric examination simply because it can be done visually without the use of specific apparatus, and to quantify the color change by using a spectrophotometer that is more commonly used and easily available compared to an epifluorescence microscope or a luminescence counter. Therefore, in the current study, a recombinant phage carrying the cytochrome c peroxidase (ccp) gene encoding the CCP enzyme was constructed for application in the colorimetric detection of $E$. coli $\mathrm{O} 157: \mathrm{H} 7$ in apple juice.

\section{MATERIALS AND METHODS}

\section{Principle of the detection method}

The principle of the detection method is schematically shown in Figure 1. In order to detect E. coli O157:H7,

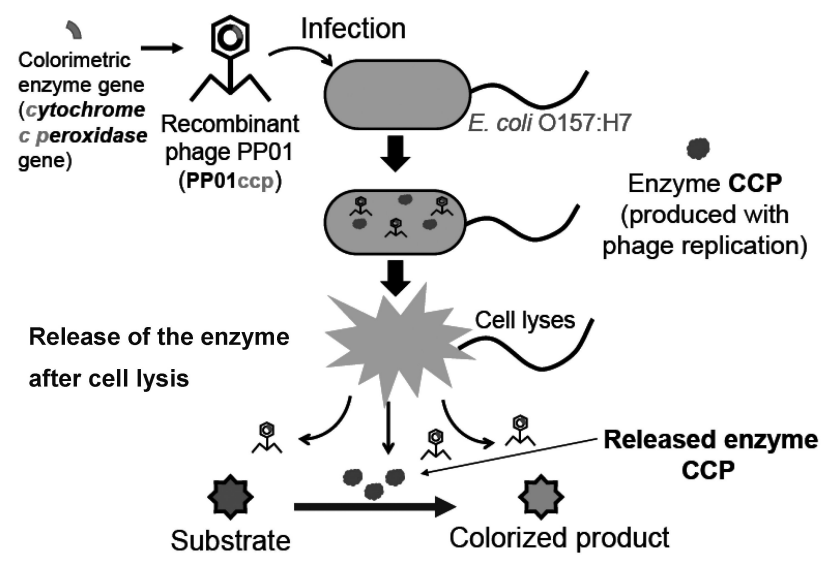

FIG. 1. Schematic diagram of principle of the detection method. The recombinant PP01ccp phage is constructed by inserting the сср gene into the genome of PP01 phage. The CCP enzyme will be produced inside the infected $E$. coli 0157:H7 cell and is then released after the cell lyses. The existence of $E$. coli $\mathrm{O} 157: \mathrm{H} 7$ in the sample is indicated by the color change caused by oxidation of the substrates through catalysis of the CCP enzyme. the ccp gene was recombined into the genome of PP01 phage to construct a recombinant PP01ccp phage. If the infection of the recombinant phage PP01ccp to $E$. coli O157:H7 occurs, the CCP enzyme will be produced inside the infected $E$. coli $\mathrm{O} 157: \mathrm{H} 7$ cell and is then released together with the newly generated phages after the cell lyses. If the substrate is added to the phage lysate, under catalysis of CCP enzyme, the substrate is oxidized resulting in color change. Therefore, E. coli O157:H7 could be detected based on the color change.

\section{Bacterial strain and bacteriophage}

E. coli O157:H7 ATCC 43888 that does not produce Stx1 and Stx2 toxins was used as the host for the PP01 phage. The wild type PP01 phage was obtained from Professor Yasunori Tanji (Tokyo Institute of Technology, Japan).

\section{Construction of the recombinant PP01ccp phage}

Oligonucleotide primers and probe used in the PCR amplification were designed based on previous study (Oda et al., 2004) where the sequences for the restriction digestion was changed, and wild type PP01 phage (PP01wt) lysate was used as the template. Fragments corresponding to the $c c p$ gene and two flanking regions were amplified and inserted into the plasmid vector pCR2.1-TOPO (Invitrogen, CA, USA) to produce the plasmid vector pCRPP01ccp (Figure 2). The $c c p$ gene was integrated into the PP01wt genome by homologous recombination. The procedures of homologous recombination and isolation of the recombinant phage PP01ccp were similar to those described in a previous study (Oda et al., 2004).

\section{Evaluation of the activity of CCP produced by the PP01ccp}

E. coli $\mathrm{O} 157: \mathrm{H} 7$ was cultivated at $37{ }^{\circ} \mathrm{C}$ until an $\mathrm{OD}_{600}$

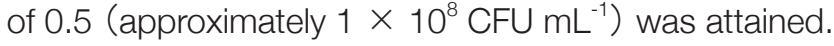
Then, the culture was divided into three aliquots, of which two aliquots were mixed with either PP01ccp or PP01wt phage lysate at a multiplicity of infection (M.O.I) of 5.0. One aliquot was left without phage addition. The aliquots were incubated at $37{ }^{\circ} \mathrm{C}$ for $1 \mathrm{~h}$ and then were passed through a $0.45-\mu \mathrm{m}$ membrane filter to obtain filtrates. In addition to the filtrates, the LB medium was also used for the assay. The cytochrome $\mathrm{C}$ from equine heart (Sigma-Aldrich, Missouri, USA) was used as a substrate for the enzymatic assay, and cytochrome c was reduced prior to the assay in accordance with the protocol described by Spinazzi et al. (2012), with minor modifications. The filtrates or the LB medium was mixed with phosphate buffer $(50 \mathrm{mM}$ $\mathrm{KH}_{2} \mathrm{PO}_{4}, \mathrm{pH}$ 6.0), cytochrome c, and $\mathrm{H}_{2} \mathrm{O}_{2}$ to obtain a 
ten-fold dilution. The final concentrations of cytochrome c and $\mathrm{H}_{2} \mathrm{O}_{2}$ were $0.9 \mu \mathrm{M}$ and $360 \mu \mathrm{M}$, respectively. The mixture was incubated at $30{ }^{\circ} \mathrm{C}$ and the $\mathrm{ABS}_{550}$ of the reaction solution was measured every minute using a spectrophotometer. All the enzyme assays were conducted in triplicate.

\section{Detection of E. coli 0157:H7 in apple juice}

Apple juice was purchased from a local supermarket and kept at $4{ }^{\circ} \mathrm{C}$. When $E$. coli $\mathrm{O} 157: \mathrm{H} 7$ culture reached $\mathrm{OD}_{600}$ of 0.5 , cell pellets were obtained by centrifugation at 4,600 $\times g, 7$ minutes. The pellets were suspended by adding an equal volume of apple juice. A ten-fold dilution series was performed in apple juice down to

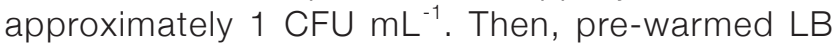
medium was added into the mixture following a ratio of apple juice to medium as showed in a previous study (Brigati et al., 2007). Each mixture was cultivated at 40 ${ }^{\circ} \mathrm{C}, 200 \mathrm{rpm}$ for a certain time and used in the phage assay with PP01ccp infection or without phage addition as shown above.

\section{RESULTS}

\section{Construction of PP01ccp}

The сcp fragment and the two flanking regions were inserted into the vector pCR2.1-TOPO to produce the vector pCRPP01ccp (Figure 2). Then, PP01ccp was produced by the homologous recombination between the vector pCRPP01ccp with the genome of PP01wt. The positive plaques were picked and suspended in the SM buffer, and PP01ccp was isolated from the suspension by repeated plaque hybridization. Integration of the сср gene into the genome of the PP01 phage was confirmed by sequencing the $c c p$ gene and the adjacent two regions in the PP01ccp

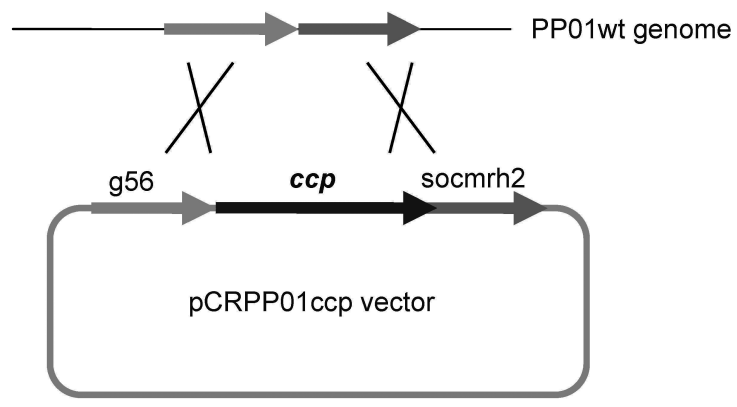

FIG. 2. Schematic diagram of homologous recombination between the constructed plasmid vector and PP01wt genome. Double crossover events occur in the g56 and socmrh2 regions of the plasmid vector and PP01wt genome, resulting in the fusion of the ccp gene into the PP01wt genome to produce the recombinant phage PP01ccp genome (data not shown). It indicated the success of the construction of the recombinant PP01ccp phage. Next, the activity of CCP enzyme produced from PP01ccp genome was examined by the detection of $E$. coli $\mathrm{O} 157: \mathrm{H} 7$ in broth.

\section{Activity of CCP expressed from PP01ccp genome}

In the enzyme assay using the lysates obtained by the PP01ccp and PP01wt infections of E. coli O157:H7, the change in the color of the reaction solution could be visually perceived (Figure 3 ). The color change of the assay using either the lysate obtained by the PP01wt infection of $E$. coli $\mathrm{O} 157: \mathrm{H} 7$ or the filtrate of the $E$. coli O157:H7 culture without phage addition was almost identical to that obtained using LB medium without any bacterial inoculation (data not shown). It was confirmed that the presence of $E$. coli $\mathrm{O} 157: \mathrm{H} 7$ or the lysis of $E$. coli $\mathrm{O} 157: \mathrm{H} 7$ by the infection of PP01wt did not affect the oxidation of the substrate. In other words, the CCP expressed from the PP01ccp genome contributed substantially to the oxidation of cytochrome c. Therefore, detection of E. coli $\mathrm{O} 157: \mathrm{H} 7$ in broth could be conducted by using the PP01ccp phage.

\section{Detection of E. coli 0157:H7 in apple juice}

The detection efficiency was examined with apple juice containing E. coli $0157: \mathrm{H} 7$ with a concentration

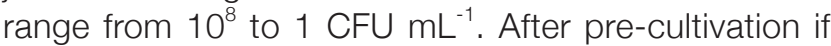
needed, PP01ccp was added or not added to the apple juice sample to carry out the phage assay. At the

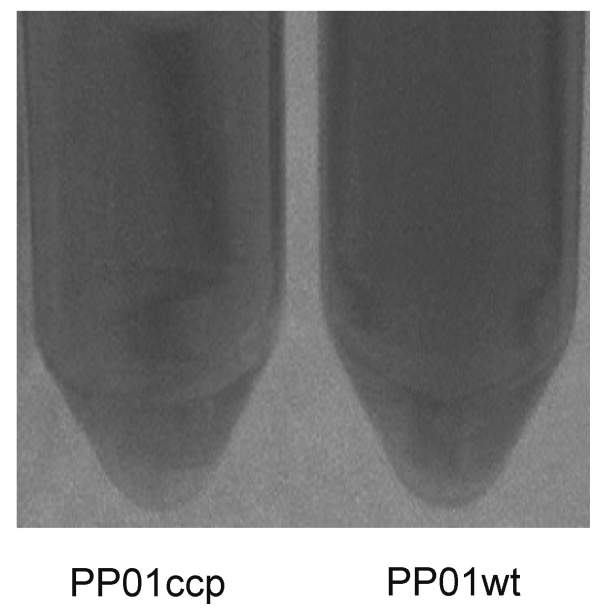

FIG. 3. Visualization of the detection based on the enzyme assay of the lysates obtained by the PP01ccp and PP01wt infections of $E$. coli O157: $\mathrm{H} 7$ against cytochrome $\mathrm{c} / \mathrm{H}_{2} \mathrm{O}_{2}$ after $3 \mathrm{~min}$. The oxidation of cytochrome $\mathrm{c}$ under catalysis of the CCP enzyme resulted in the color change from the original red color to the orange-yellow color in the PP01ccp tube. The original red color showed almost no change in the PP01wt tube. 


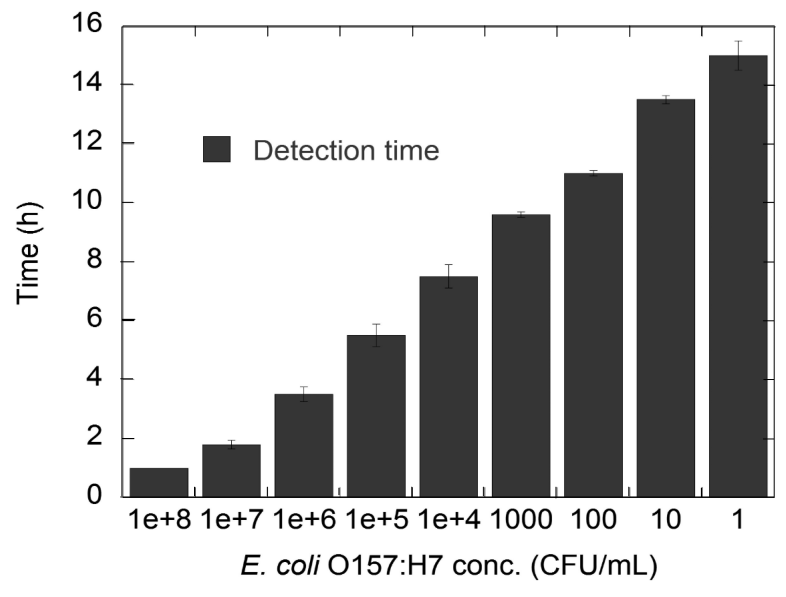

FIG. 4. Response time profile of the detection of E. coli 0157:H7 in apple juice. Detection time involved the time in pre-cultivation and the phage assay. Error bars indicating 95\% confidence intervals for the averaged values $(n=3)$ are not graphically detectable at some points as the intervals were too narrow.

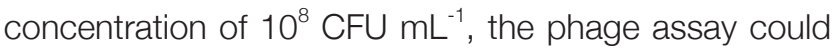
detect $E$. coli $\mathrm{O} 157: \mathrm{H} 7$ without the pre-cultivation step. At lower concentrations, the pre-cultivation step was needed. Detection time for the whole process (involving pre-cultivation and phage assay) is described in Figure 4. Time required to detect the highest and lowest concentrations of $E$. coli $\mathrm{O} 157: \mathrm{H} 7$ was about $1 \mathrm{~h}$ and $15 \mathrm{~h}$, respectively.

\section{DISCUSSION}

E. coli $\mathrm{O} 157: \mathrm{H} 7$ causes approximately 73,000 cases of illness in USA annually with the main epidemiological symptoms of severe diarrhea and HUS. The largest E. coli O157: $\mathrm{H} 7$ outbreak was reported in January, 1993 with more than 700 who became ill people and 4 children who died (Rangel et al., 2002). E. coli O157:H7 outbreaks have been also reported in other developed countries (Isaacson et al., 1993; Chapman et al, 1989; Armstrong et al., 1996). In Vietnam, information of $E$. coli $\mathrm{O} 157: \mathrm{H} 7$ contamination in environmental and food samples is still very limited. However, it is expected that contamination of $E$. coli O157:H7 in those samples in Vietnam with poor hygiene conditions is more prevalent than in other developed countries. Therefore, the development of simple and cheap methods used to detect E. coli O157:H7 would play an important role in preventing serious diseases caused by E. coli O157: $\mathrm{H} 7$.

The detection method developed in this study can be considered as the first successfully performed phagebased colorimetric detection of E. coli O157:H7. The enzyme assay was conducted in few minutes against cytochrome $\mathrm{c} / \mathrm{H}_{2} \mathrm{O}_{2}$ and the color change could be easily recognized by the naked eye without the need for any apparatuses. In addition, the color change could be quantified using a spectrophotometer that is relatively commonly used and more easily available compared to an epifluorescence microscope or a luminescence counter that are required in the previously developed phage-based methods. The convenience is a strong point compared to the other phage-based detection methods.

Animal feces are considered as the original source of E. coli $0157: \mathrm{H} 7$. The feces are normally treated by composting to produce compost that is used on farms as a fertilizer to cultivate plants. During the composting process, E. coli O157:H7 in the feces is eliminated by high temperatures generated inside the composting zone. The composting process is usually performed by farmers especially in developing countries and may not result in mature compost that completely eliminates $E$. coli O157:H7 from the original feces. At apple farms, during harvesting season, E. coli $\mathrm{O} 157: \mathrm{H} 7$ from the land can easily be transmitted to apples. Unpasteurized fresh apple juice is still consumed especially in the appleproducing regions in the world because with its $\mathrm{pH}$ of less than 4.6 it is considered to be of low risk for the transmission of pathogenic bacteria. However, it was demonstrated that $E$. coli $0157: \mathrm{H} 7$ can survive at a $\mathrm{pH}$ as low as 2.0 (Miller \& Kaspar, 1994; Conner \& Kotrola, 1995). In addition, the infection of E. coli O157:H7 via consuming the unpasteurized fresh apple juice has been reported (Steele et al., 1982; Besser et al., 1993; Cody et al., 1999).

In the current study, apple juice was artificially contaminated by E. coli $\mathrm{O} 157: \mathrm{H} 7$ and addition of pre-warmed LB medium in the suspension step would favor the growth of $E$. coli $0157: \mathrm{H} 7$. The ratio of the volume of the pre-warmed LB medium to that of the contaminated apple juice followed the ratio employed in a previous study (Brigati et al., 2007). The method in the current study enabled the detection of concentrations of $E$. coli $\mathrm{O} 157: \mathrm{H} 7$ as low as $1 \mathrm{CFU} \mathrm{\textrm {mL } ^ { - 1 }}$ in apple juice, while the phage-based bioluminescent method (Brigati et al., 2007) could not detect the $E$. coli $\mathrm{O} 157: \mathrm{H} 7$ at less than $10^{4} \mathrm{CFU} \mathrm{mL}{ }^{-1}$ due to the interference of the apple juice to the system. To overcome the interference of the apple juice in the detection of such low concentrations of $E$. coli O157:H7, Ripp et al. (2008) centrifuged the apple juice to discard the supernatant to obtain and to concentrate the cell pellet that was then suspended in LB medium prior to the pre-cultivation. In this way, such a low

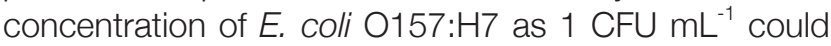
be detected after $22 \mathrm{~h}$. 
Compared to previous phage-based bioluminescent methods, the method in the current study is more advantageous in detection of $E$. coli $\mathrm{O} 157: \mathrm{H} 7$ in apple juice. Firstly, the method could detect E. coli O157:H7

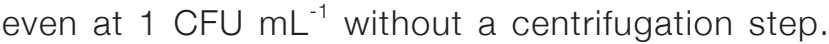
Secondly, the method just takes about $15 \mathrm{~h}$ to detect the E. coli $\mathrm{O} 157: \mathrm{H} 7$ at a concentration as low as $1 \mathrm{CFU}$ $\mathrm{mL}^{-1}$ while the phage-based bioluminescent method needs about $22 \mathrm{~h}$ as mentioned above. Therefore, the method was demonstrated to be faster and simpler than previous phage-based bioluminescent methods in the detection of E. coli O157:H7 in apple juice. In future studies, the method will be examined in the detection of E. coli O157:H7 in other food samples such as milk, vegetables, meats, etc.

\section{ACKNOWLEDGEMENTS}

We thank Prof. Yasunori Tanji at Tokyo Institute of Technology, Japan for providing us with the PP01wt phage and Prof. Nguyen Thuy Huong at Ho Chi Minh City University of Technology, Vietnam for supplying us with some experimental materials.

\section{REFERENCES}

Armstrong, G. L., Hollingsworth, J., and Morris, J. G. (1996) Emerging foodborne pathogens: Escherichia coli O157:H7 as a model of entry of a new pathogen into the food supply of the developed world. Epidemiol. Rev., 18, 29-51.

Besser, R. E., Lett, S. M., Weber, J. T., Doyle, M. P., Barrett, T. J., Wells, J. G., and Griffin, P. M. (1993) An outbreak of diarrhea and hemolytic uremic syndrome from Escherichia coli 0157:H7 in fresh-pressed apple cider. J. Am. Med. Assoc., 269, 2217-2220.

Brigati, J. R., Ripp, S. A., Johnson, C. M., lakova, P. A., Jegier, P., and Sayler, G. S. (2007) Bacteriophage-based bioluminescent bioreporter for the detection of Escherichia coli 0157:H7. J. Food. Protect., 70, 1386-1392.

Chapman, P. A., Wright, D. J., and Norman, P. (1989) Verotoxin-producing Escherichia coli infections in Sheffield: Cattle as a positive source. Epidem. Inf., 102, 439-445.

Chekabab, S. M., Paquin-Veillette, J., Dozois, C. M., and Harel, J. (2013) The ecological habitat and transmission of Escherichia coli O157:H7. FEMS. Microbiol. Lett., 341, $1-12$.

Cody, S. H., Glynn, M. K., Farrar, J. A. et al. (1999) An outbreak of Escherichia coli O157:H7 infection from unpasteurized commercial apple juice. Ann. Intern. Med., 130, 202-209.

Conner, D. E., and Kotrola, J. S. (1995) Growth and survival of Escherichia coli 0157: $\mathrm{H} 7$ under acidic conditions. Appl. Environ. Microbiol., 61, 382-385.

Fode-Vaughan, K. A., Maki, J. S., Benson, J. A., and Collins, M. L. P. (2003) Direct PCR detection of Escherichia coli 0157:H7. Lett. Appl. Microbiol., 37, 239-243.

Fujisawa, T., Sata, S., Aikawa, K., Takahashi, T., Yamai, S. and Shimada, T. (2000) Modification of sorbitol MacConkey medium containing cefixime and tellurite for isolation of Escherichia coli 0157:H7 from radish sprouts. Appl. Environ. Microbiol., 66, 3117-3118.

Isaacson, M., Canter, P. H., Effler, P., Arntzen, L., Bomans, P., and Heenan, R. (1993) Haemorrhagic colitis epidemic in Africa. Lancet, 341, 961-961.

Jinneman, K. C., Yoshitomi, K. J., and Weagant, S. D. (2003) Multiplex real-time PCR method to identify Shiga toxin genes stx1 and stx2 and Escherichia coli $0157: \mathrm{H} 7 / \mathrm{H}-$ serotype. Appl. Environ. Microbiol., 69, 6327-6333.

Mead, P. S., Slutsker, L., Dietz, V., McCaig, L. F., Bresee, J. S., Shapiro, C., Griffin, P. M., and Tauxe, R. V. (1999) Food-related IIIness and death in the United States. Emerg. Infect. Dis., 5, 607-625.

Miller, L. G., and Kaspar, C. W. (1994) Escherichia coli 0157. $\mathrm{H} 7$ acid tolerance and survival in apple cider. J. Food Protect., 57, 460-464.

Oda, M., Morita, M., Unno, H., and Tanji, Y. (2004) Rapid detection of Escherichia coli $\mathrm{O} 157: \mathrm{H} 7$ by using green fluorescent protein-labeled PP01 bacteriophage. Appl. Environ. Microbiol., 70, 527-534.

Possé, B., Zutter, L. D., Heyndrickx, M., and Herman, L. (2008) Novel differential and confirmation plating media for Shiga toxin-producing Escherichia coli serotypes O26, 0103, 0111, 0145 and sorbitol-positive and-negative 0157. FEMS. Microbiol. Lett., 282, 124-131.

Rangel, J. M., Sparling, P. H., Crowe, C., Griffin, P. M., and Swerdlow, D. L. (2002) Epidemiology of Escherichia coli 0157:H7 outbreaks, United States, 1982-2002. Emerg. Infect. Dis., 11, 603-609.

Ripp, S., Jegier, P., Johnson, C. M., Brigati, J. R., and Sayler, G. S. (2008) Bacteriophage-amplified bioluminescent sensing of Escherichia coli O157:H7. Anal. Bioanal. Chem., 391, 507-514.

Spinazzi, M., Casarin, A., Pertegato, V., Salviati, L., and Angelini, C. (2012) Assessment of mitochondrial respiratory chain enzymatic activities on tissues and cultured cells. Nat. Protoc., 7, 1235-1246.

Steele, B. T., Murphy, N., Arbus, G. S., and Rance, C. P. (1982) An outbreak of hemolytic uremic syndrome associated with ingestion of fresh apple juice. J. Pediatr., 101, 963-965. 